\title{
A new continuous high-resolution detection system for sulphate in ice cores
}

\author{
Matthias BIGLER, ${ }^{1}$ Anders SVENSSON, ${ }^{1}$ Jørgen Peder STEFFENSEN, ${ }^{1}$ \\ Patrik KAUFMANN ${ }^{2}$ \\ ${ }^{1}$ Ice and Climate Research, Niels Bohr Institute, University of Copenhagen, Juliane Maries Vej 30, \\ DK-2100 København Ø, Denmark \\ E-mail: bigler@gfy.ku.dk \\ ${ }^{2}$ Climate and Environmental Physics, Physics Institute, University of Bern, Sidlerstrasse 5, \\ $\mathrm{CH}-3012$ Bern, Switzerland
}

\begin{abstract}
Sulphate $\left(\mathrm{SO}_{4}{ }^{2-}\right)$ is a major ion found in polar ice cores and is related to different aerosol sources and processes. Explosive volcanic eruptions, even far away, can cause distinct sulphate peaks in ice core records. Thus, a robust sulphate detection system which is suitable for fieldwork and which enables the measurement of sulphate at high temporal resolution is of great interest. In this study, we present the adaptation of a new continuous flow analysis system for sulphate that is based on a spectrophotometric method using dimethylsulfonazo III and an inline reactor column containing barium sulphate particles. The method shows a detection limit of $\sim 70 \mathrm{ng} \mathrm{g}^{-1}$ and a linear range up to at least $3000 \mathrm{ng} \mathrm{g}^{-1}$. It is simple, robust and less prone to interferences compared to the previously used method.
\end{abstract}

\section{INTRODUCTION}

Ice core records of irreversibly deposited aerosol constituents carry comprehensive information on changes in their atmospheric long-range transport and source areas far back in time (Legrand and Mayewski, 1997; Wolff and others, 2006). Measured at high temporal resolution they may reveal even persistent seasonal deposition cycles (Sommer and others, 2000; Bigler and others, 2002), a prerequisite for stratigraphic dating (Rasmussen and others, 2006). Some of the ice core records have distinct peaks related to aerosols superimposed, caused by explosive volcanic eruptions. Thus, such time series can be used to estimate occurrence rates of volcanic events to assess possible climatic effects (Crowley, 2000; Hegerl and others, 2006). Furthermore, these unique archives of past volcanic activity can serve to pin down the dating of ice cores and other paleoarchives by identifying common reference horizons. Explosive volcanic eruptions emit large amounts of ash particles (e.g. tephra) and gases (mainly $\mathrm{SO}_{2}$ ) into the atmosphere, where oxidation and gas-to-particle conversion of $\mathrm{SO}_{2}$ to sulphuric acid $\left(\mathrm{H}_{2} \mathrm{SO}_{4}\right)$ occurs. Volcanic events are therefore recorded in ice cores mainly as acidic peaks (Hammer and others, 1980; Clausen and others, 1997), sulphate $\left(\mathrm{SO}_{4}{ }^{2-}\right)$ peaks (Zielinski and others, 1996; Bigler and others, 2002; Castelleno and others, 2005) and tephra (Grönvold and others, 1995; Mortensen and others, 2005). Continuous high-resolution measurements are not feasible for tephra, but they can be carried out for $\mathrm{SO}_{4}{ }^{2-}$ and the acidic content of the ice. However, the latter is only indirectly possible through conductivity measurements on solid ice (Electrical Conductivity Measurements (ECM) and Dielectric Profiling (DEP)) or on meltwater of continuously melted ice samples (electrolytical conductivity). Both ECM and DEP can be weakened or even obliterated in sections with high dust levels due to the increased alkalinity, whereas electrolytical conductivity can result in ambiguous peaks, as it contains a bulk signal of all ionic components present in the ice. Therefore, large $\mathrm{SO}_{4}{ }^{2-}$ peaks must be considered as the most reliable indicator of volcanic activity recorded in ice cores.

Ion chromatography (IC) is a common and very reliable method to measure $\mathrm{SO}_{4}{ }^{2-}$ in ice core samples (Legrand and Delmas, 1987; Littot and others, 2002). However, it is time consuming to measure numerous samples to achieve highresolution records, especially when each sample has to be cut and decontaminated manually. Therefore, the Continuous Flow Analysis (CFA) measuring technique has become the method of choice to obtain long ice core time series of several important aerosol constituents with a depth resolution of $\sim 1 \mathrm{~cm}$, which leads to an unprecedented temporal resolution (considering the actual annual layer thickness) (Sigg and others, 1994; Röthlisberger and others, 2000; Bigler and others, 2006). The strength of a CFA system is twofold: (1) The melting device provides a continuous uncontaminated sample stream of meltwater from continuously melted subsections of the ice core. This is because only the inner part of the subsection that was never in contact with ambient air is drained off, whereas the possibly contaminated water from the outer part is rejected. (2) The immediate detection of the constituents of interest by means of fluorescence and absorption spectrophotometric methods leads to a very high temporal data resolution. Although the CFA melting device was recently used for IC measurements, either by using an autosampler or by direct coupling to an adapted fast IC (Udisti and others, 2000; Osterberg and others, 2006), the CFA detection methods are still unprecedented in terms of temporal data resolution with respect to the length of ice core records. Therefore the availability of a CFA $\mathrm{SO}_{4}{ }^{2-}$ detection system is highly desirable. A first attempt at measuring $\mathrm{SO}_{4}{ }^{2-}$ by $\mathrm{CFA}$ was made some years ago (Bigler, 2000; Bigler and others, 2002) and records were obtained from the glacial ( 110 to $\sim 10 \mathrm{kyr} B P$ ) part of the North Greenland Ice Core Project (NGRIP) deep ice core (Bigler, 2004; North Greenland Ice Core Project members, 2004) and from a shallow firn core taken in Northeast 


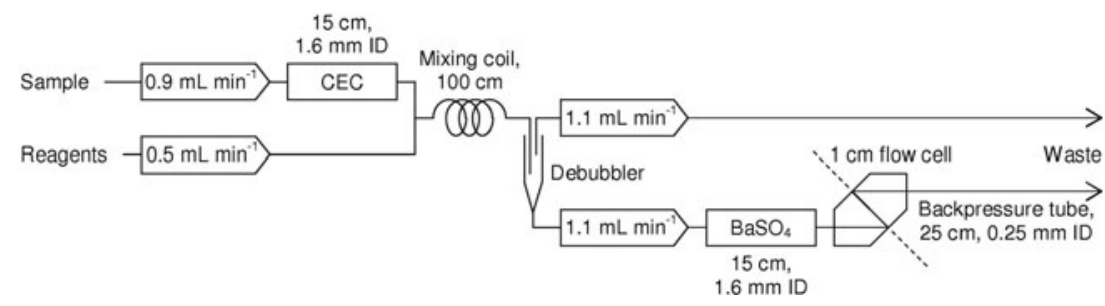

Fig. 1. Setup of the $\mathrm{CFA} \mathrm{SO}_{4}{ }^{2-}$ detection system. Features include the inline Cation Exchange Column (CEC), the overflow debubbler and the inline $\mathrm{BaSO}_{4}$ reactor column. Flow rates are given for each pump tube of the peristaltic pump. The broken line indicates the fibre optic cables from the flow cell to the lamp and to the detector, respectively.

Greenland (NGT B20) (Bigler and others, 2002). However, the method used for the $\mathrm{SO}_{4}{ }^{2-}$ detection based on Methylthymol Blue (MTB) (Madsen and Murphy, 1981) turned out to be relatively delicate for routine field measurements, especially at low concentration levels, showing occasional baseline instabilities, a non-linear calibration curve, a too high Limit Of Detection (LOD) and strong interferences from bivalent cations such as calcium and magnesium. Ideally, the new $\mathrm{CFA} \mathrm{SO}_{4}{ }^{2-}$ detection system should cover a concentration range of $\mathrm{SO}_{4}{ }^{2-}$ in polar ice cores from 10 to $10000 \mathrm{ng} \mathrm{g}^{-1}$. Here we present and discuss the adaptation of a new CFA $\mathrm{SO}_{4}{ }^{2-}$ detection method.

\section{METHOD AND OPTIMIZATION}

\section{Overview}

Based on an extensive literature investigation, a Flow Injection Analysis (FIA) method using dimethylsulfonazo III (DMS-III) as $\mathrm{SO}_{4}{ }^{2-}$ indicator (Burakham and others, 2004) was found to be most promising as a starting point for our adaptation to a CFA method. A similar FIA method was used already by Yang and others $(1997 a, b)$, with reference to the initial publication of Kondo and others (1982) using DMS-III. The FIA DMS-III method has many important features. Depending on the $\mathrm{SO}_{4}{ }^{2-}$ concentration in the sample, barium sulphate $\left(\mathrm{BaSO}_{4}\right)$ precipitates and causes the dissociation of Ba-DMS-III complexes. The decreasing absorbance at $662 \mathrm{~nm}$ is monitored continuously. An inline reactor column containing $\mathrm{BaSO}_{4}$ particles (Burakham and others, 2004) promotes the efficiency and reproducibility of the slow liquid-solid reaction and the radial mixing of sample and reagent (Yang and others, 1997a). Furthermore, the sample water has to be pre-treated in an inline Cation Exchange Column (CEC) to avoid interferences with specific bivalent cations (i.e. $\mathrm{Ca}^{2+}$ and $\mathrm{Mg}^{2+}$ ). The given LOD ranges from $30 \mathrm{ngg}^{-1}$ (Burakham and others, 2004) to $80 \mathrm{ngg}^{-1}$ (Yang and others, 1997a), while the precision (relative standard deviation of repeated similar measurements) is found to be between $1 \%$ (Kondo and others, 1982) and $1.6 \%$ (Burakham and others, 2004) for concentrations of $\sim 1000 \mathrm{ng} \mathrm{g}^{-1} \mathrm{SO}_{4}{ }^{2-}$. Figure 1 provides an overview of the new $\mathrm{CFA} \mathrm{SO}_{4}{ }^{2-}$ set-up and each of the components are described in the following sections.

\section{Reagent}

Barium $\left(\mathrm{Ba}^{2+}\right)$ reacts with DMS-III at an equimolar ratio. According to Kondo and others (1982) it is appropriate to fix the molar ratio of $\mathrm{Ba}^{2+}$ to DMS-III in the reagent at $0.7-1$. The high ethanol content of the reagent leads to an increased absorbance, while the $\mathrm{pH}$ value of the merged sample and reagents flow has to be kept between 3.5 and 5.5 with an equimolar solution of chloroacetic acid $\left(\mathrm{ClCH}_{2} \mathrm{COOH}\right)$ and sodium chloroacetate $\left(\mathrm{ClCH}_{2} \mathrm{COONa}\right)$, which is a buffer with $\mathrm{pH}$ 2.9. The addition of potassium nitrate $\left(\mathrm{KNO}_{3}\right)$ to the reagent maintains a constant ionic strength, which prevents baseline fluctuations. However, the Ba-DMS-III concentration in the reagent is the most important parameter and can be used to optimize the method for the desired $\mathrm{SO}_{4}{ }^{2-}$ concentration range. While low reagent concentrations cause a low signal-to-noise ratio, too high reagent concentrations lead to deviations of the calibration curve from linearity as well as a lower sensitivity for low $\mathrm{SO}_{4}{ }^{2-}$ concentration levels and therefore a higher LOD. We found suitable concentrations of $80 \mu \mathrm{M}$ for DMS-III and $56 \mu \mathrm{M}$ for $\mathrm{BaCl}_{2}$ in the reagent somewhat higher than in the initial publications (Kondo and others, 1982; Yang and others, 1997a; Burakham and others, 2004). The reagent preparation is described in the following paragraph.

All reagents were of analytical grade and prepared with

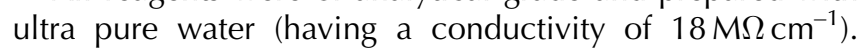
Included are: $8 \mathrm{~mL} 0.01 \mathrm{M}$ DMS-III solution $(\mathrm{M}=$ $760.66 \mathrm{~g} \mathrm{~mol}^{-1}$, Sigma-Aldrich); $5.6 \mathrm{~mL} 0.01 \mathrm{M} \mathrm{BaCl}_{2}$ solution $\left(\mathrm{M}=208.25 \mathrm{~g} \mathrm{~mol}^{-1}\right.$, Merck); $5 \mathrm{~mL} 1 \mathrm{M} \mathrm{KNO}_{3}$ solution $\left(\mathrm{M}=101.11 \mathrm{~g} \mathrm{~mol}^{-1}\right.$, Merck); $20 \mathrm{~mL}$ buffer solution (pH 2.9) consisting of a 1:1 mixture (K. Higuchi, personal communication) of $1 \mathrm{M}$ chloroacetic acid $\left(\mathrm{M}=94.50 \mathrm{~g} \mathrm{~mol}^{-1}\right.$, Merck) and $1 \mathrm{M}$ sodium chloroacetate $\left(M=116.48 \mathrm{~g} \mathrm{~mol}^{-1}\right.$, Merck); $700 \mathrm{~mL}$ ethanol absolute (Merck); and $\sim 260 \mathrm{~mL}$ ultra pure water to get $1000 \mathrm{~mL}$ reagent solution. It is relatively stable when ultraviolet light is avoided (S. Motomizu, personal communication, 2005). $\mathrm{A} \mathrm{SO}_{4}{ }^{2-}$ stock standard solution of $\mathrm{Na}_{2} \mathrm{SO}_{4}$ in water (Merck) was used to dilute appropriate working standard solutions.

\section{$\mathrm{BaSO}_{4}$ reactor column}

Burakham and others (2004) packed crushed $\mathrm{BaSO}_{4}$ with a particle size of about $90 \mu \mathrm{m}$ in their reactor column. However, this material was neither commercially available from fine chemical suppliers, nor could we get detailed information about possible extraction procedures from the authors. $\mathrm{BaSO}_{4}$ is a white powder of low solubility and high density and is used as a non-fading and chemically stable pigment, roentgen contrast medium and filler material in paper, rubber or heavy concrete. It is produced by disintegration of the mineral barite (Schwerspat) and controlled precipitation of $\mathrm{Ba}^{2+}$ salts with sulphuric acid. A method of producing particle sizes between 0.1 and $10 \mu \mathrm{m}$ is given by Amirzadeh-Asl and Schwarz (2001). Because of the larger size, we therefore assume that the above-mentioned crushed $\mathrm{BaSO}_{4}$ has to be barite mineral particles and not precipitated $\mathrm{BaSO}_{4}$. A barite test sample 

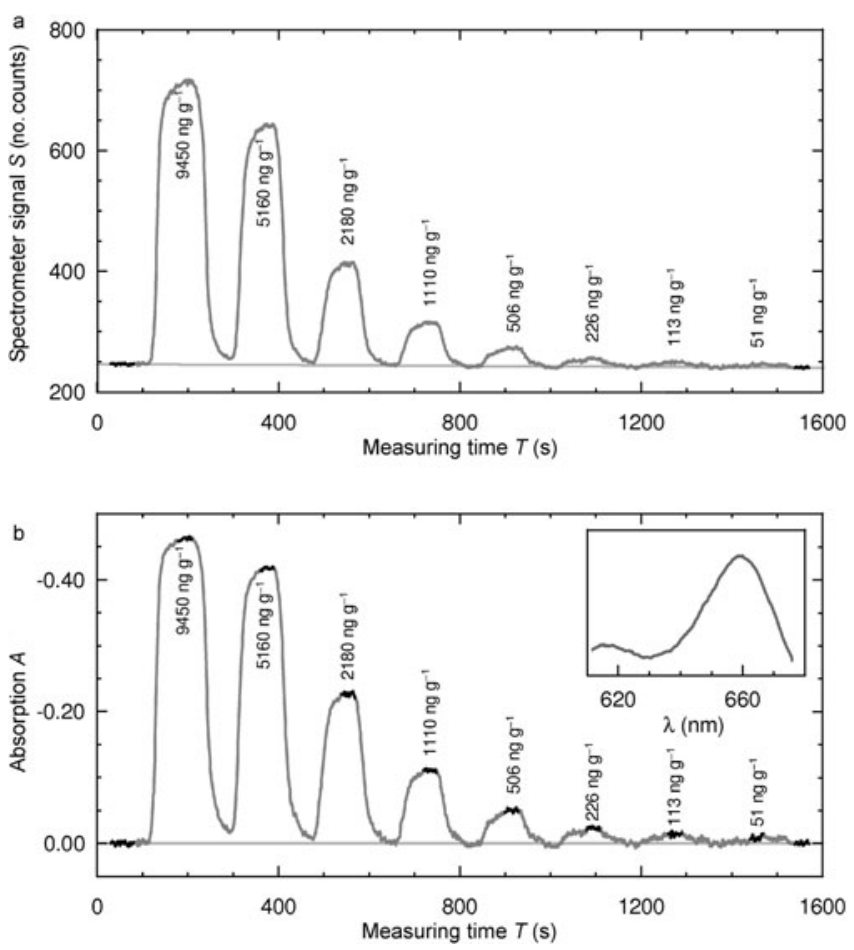

Fig. 2. (a) Spectrometer signal $S$ (number of counts) of a $\mathrm{SO}_{4}{ }^{2-}$ standard series (dark grey) with given concentration values. The baseline (light grey) is calculated by linearly interpolating between two sections of blank measurements (black) before and after the standards. (b) Calculated absorption values $A$ of the standard series (dark grey) with respect to the zero line (light grey). Plateau values used to calculate the calibration curve (Fig. 3) are highlighted in black. The insertion shows the measured absorption spectrum $A$ (in arbitrary units) with a maximum around the wavelength $\lambda=659 \mathrm{~nm}$.

was kindly provided by Sachtleben Chemie (Germany), mined from the Clara Mine deposit at Wolfach. The crude ore was dressed by heavy media separation, flotation and drying processes. The specific particle distribution, with a medium particle size of $\sim 23 \mu \mathrm{m}$, was achieved by milling and air sifting. The final product has a $\mathrm{BaSO}_{4}$ content of $\sim 98 \%$ (K.-H. Schwarz, personal communication, 2006). By sieving with a $90 \mu \mathrm{m}$ sieve we obtained the fraction of larger particles ( $\sim 30 \%$ of the total amount) and washed it 10 times with ultra pure water. Subsequently, reactor columns with $1.6 \mathrm{~mm}$ Inner Diameter (ID) were filled (details below). We tested different column lengths of 4$24 \mathrm{~cm}$ and found that $15 \mathrm{~cm}$ is suitable for our set-up. Shorter columns seem to enhance baseline drifts, while longer ones can cause pressure problems. We observed that the length of the column does not affect the absorbance very much. As slight baseline drifts are observed after $\sim 10$ 12 hours of usage, the column has to be rinsed with ultra pure water for 1 hour. Subsequently, the baseline returns to the initial level again. A column can be used for 1 month with unchanged sensitivity and reproducibility (Burakham and others, 2004).

\section{Cation exchange column (CEC)}

In contrast to monovalent ions, bivalent cations such as calcium $\left(\mathrm{Ca}^{2+}\right)$ and magnesium $\left(\mathrm{Mg}^{2+}\right)$ interfere with the detection method (Kondo and others, 1982; Yang and others, 1997a; Burakham and others, 2004). Therefore, an inline
CEC has to be used. Burakham and others (2004) reported that $\mathrm{Na}^{+}$-type cation exchange resins yield better results than those of $\mathrm{H}^{+}$-type. As a consequence, we used Dowex $50 \mathrm{~W} \times 8, \mathrm{Na}^{+}$-form with a particle size of $75-150 \mu \mathrm{m}$ and analytical grade (Fluka) in a $15 \mathrm{~cm}$ long, $1.6 \mathrm{~mm}$ ID column (details below). The CEC can be regenerated by pumping through a $20 \%$ sodium chloride solution for a few minutes, which was performed daily. The CEC was tested and found to be appropriate to prevent interferences caused by bivalent cations in typical glacial ice core samples from Greenland. A solution containing $2000 \mathrm{ngg}^{-1} \mathrm{Ca}^{2+}$ and $1000 \mathrm{ngg}^{-1}$ $\mathrm{Mg}^{2+}$, never observed in high-resolution CFA data from polar ice cores previously (Bigler, 2004), caused no noticeable interference. A smaller column volume could be chosen for interglacial or Antarctic ice samples with lower impurity content.

\section{Set-up}

A characteristic feature of the applied $\mathrm{SO}_{4}{ }^{2-}$ detection method is the formation of bubbles due to heat production when merging the ethanolic reagent with the sample water stream. During the experimental testing it became apparent that bubble formation has to be prevented by all means as it causes a very noisy signal and baseline instabilities. This problem was solved by (1) using a lower ethanol concentration in the reagent compared to the initial publication (Kondo and others, 1982), as proposed by Burakham and others (2004); (2) inserting an overflow debubbler into the set-up, which removes large bubbles and (3) by adding a backpressure tube after the flow cell, which prevents additional small bubbles from forming in the light path of the flow cell. According to the law of Hagen-Poiseuille the difference pressure of a $25 \mathrm{~cm}$ long backpressure tube with an ID of $0.25 \mathrm{~mm}$ is $\sim 0.5$ bar at a flow rate of $1.1 \mathrm{~mL} \mathrm{~min}^{-1}$ (estimated dynamic viscosity of an ethanol-water mixture at $20^{\circ} \mathrm{C}$ is $0.0011 \mathrm{~N} \mathrm{~s} \mathrm{~m}^{-2}$ ). Altogether, the two inline columns and the backpressure tube in the set-up cause a high backpressure, so that the peristaltic pumps run at their pressure limit and exhibit pulsating pumping. This leads to irregular mixing of sample and reagents and therefore noisy signals. This was a further reason to decouple the set-up by inserting an overflow debubbler. Additionally, a mixing coil with an optimized length of $100 \mathrm{~cm}$ in front of the debubbler was found to support a more regular mixing.

The complete set-up shown in Figure 1 was made of Teflon tubing $(1.6 \mathrm{~mm}$ Outer Diameter (OD), $0.5 \mathrm{~mm}$ ID, PFA HP plus). Due to the relatively high pressure within the whole set-up, all connections were screwed using standard 1/4-28 fittings and peristaltic tubing adapters (all items from Upchurch, USA). Flow rates (given in Fig. 1) were adjusted using pump tubes with different inner diameters and appropriate pump rates of the peristaltic pumps (from Ole Dich, Denmark). The pump tubes are solvent-resistant for ethanol containing streams (PharMed/Ismapren) and made of Tygon Long Flex Life (LFL) for all other lines (both from Ismatec, Switzerland). They were checked regularly. We found that changing the flow rate did not have a remarkable effect, except for reducing absorbance values by a small amount at lower flow rates. The overflow debubbler was made of a downwards-mounted pipette tip with the sample inlet and overflow tubes inserted from the top and the outlet connected to the tip at the bottom. The overflow tube was positioned slightly higher than the sample inlet tube to prevent contamination. By shifting the position of these two 
tubes it was possible to reduce the mixing volume to $40 \mu \mathrm{L}$ while still maintaining an efficient removal of bubbles in the flow. Columns were built by using standard 1/4-28 fittings and unions to connect the flow lines with the column tubes made of Teflon tubing $(3.2 \mathrm{~mm}$ OD, $1.6 \mathrm{~mm}$ ID, PFA HP plus). On both sides a frit-in-a-ferrule (for $3.2 \mathrm{~mm}$ OD, $2 \mu \mathrm{m}$ SST, PCTFE) was used to keep the filling in the columns (all items from Upchurch, USA). To run standard series automatically and to switch between sample and blank, actuated medium pressure ceramic valves (V-1461-DC 6-port-2position and V-1471-DC 7-port-6-position from Upchurch, USA) were used.

\section{Absorption detector}

A miniature combination deuterium and tungsten halogen light source (DT-Mini-2-GS from FIAlab/Ocean Optics, USA) was employed. However, only the halogen bulb was switched on for this application. To detect the absorption signal a flow cell with a $10 \mathrm{~mm}$ optical path (SMA-Z- $\mu$ vol, Ultem, with fused silica windows, from FIAlab, USA) was used. Fibre optic cables conducted the light from the lamp to the flow cell and from there to the spectrometer. The detector consisted of one channel of a three-channel spectrometer (USB2000-UV-VIS, ADC1000-USB analoguedigital converter from FIAlab/Ocean Optics, USA). We made use of the automatic correction function for electrical dark signals. Maximum absorbance was found at a wavelength of $659 \mathrm{~nm}$ (insertion in Fig. 2), slightly lower than in the initial publications. However a maximum signal-to-noise ratio was achieved by integrating the spectrometer signal over the wavelength interval $654-663 \mathrm{~nm}$. All connections to the measuring computer were made directly or via RS-233 to USB converters to one USB hub. The control and data acquisition program with a measuring sequence time of $1 \mathrm{~s}$ was written in LabVIEW 8 (National Instruments, USA) using the driver software OOILVD (from Ocean Optics/FIAlab) to control the spectrometer.

\section{Characteristics of the new method}

Figure 2 shows the spectrometer signal $S$ of a $\mathrm{SO}_{4}{ }^{2-}$ standard series. The baseline $S_{0}$ is calculated by linearly interpolating between two sections of blank measurements (ultra pure water) at the beginning and the end. The absorption $A$ (Fig. 2b) is calculated as $A=\log _{10}\left(S_{0} / S\right)=\varepsilon / C$, where $\varepsilon$ is the extinction coefficient in $\left(\mathrm{ng} \mathrm{g}^{-1}\right)^{-1} \mathrm{~cm}^{-1}, I$ the light path length in the flow cell in $\mathrm{cm}$ and $\mathrm{C}$ the $\mathrm{SO}_{4}{ }^{2-}$ concentration in $\mathrm{ng} \mathrm{g}^{-1}$. Plateau values of the standards define the calibration curve shown in Figure 3. The characteristics of our new $\mathrm{SO}_{4}{ }^{2-}$ method are an extinction coefficient of $\sim 0.0001\left(\mathrm{ng} \mathrm{g}^{-1}\right)^{-1} \mathrm{~cm}^{-1}$ and a LOD of $\sim 70 \mathrm{ng} \mathrm{g}^{-1}$, approximately double the value of $30 \mathrm{ng} \mathrm{g}^{-1}$ given in Burakham and others (2004) and higher than desired for our CFA SO${ }_{4}{ }^{2-}$ detection method to measure polar ice samples. However, a value of this order of magnitude is probably the lowest possible due to the solubility of $\mathrm{BaSO}_{4}$ in aqueous solution (S. Motomizu, personal communication, 2005). The upper limit of the linear calibration curve is $\sim 3000 \mathrm{ng} \mathrm{g}^{-1}$, somewhat lower than desired. Nevertheless, it still covers almost all the volcanic peak values expected in polar ice cores. By applying a non-linear calibration curve or by using a higher Ba-DMS-III concentration in the reagent (with the disadvantage of a lower sensitivity at low concentration levels) this upper limit could be raised.

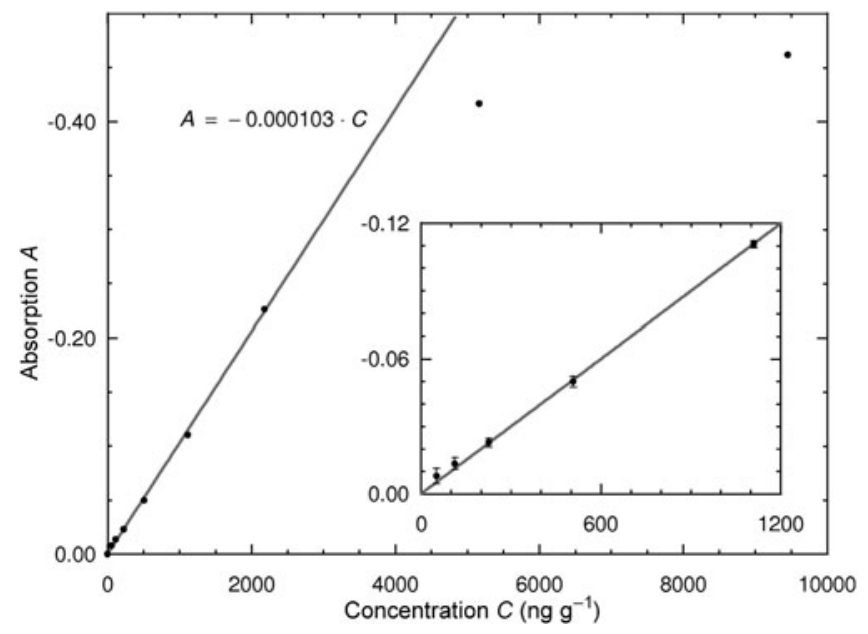

Fig. 3. Calibration curve between measured absorption values and given standard concentrations (points). To calculate the linear fit $(A=-0.000103 C)$ the two highest values were excluded to account for the deviation from linearity at high concentration levels. The insertion contains an enlargement of the lowest concentration values showing a satisfactory linearity (error bars correspond to the standard deviations of the standard plateaus in Fig. 2).

\section{CONCLUSIONS}

A new $\mathrm{CFA} \mathrm{SO}_{4}{ }^{2-}$ detection method has been successfully implemented. It is based on an existing FIA method using Ba-DMS-III complexes in the spectrophotometric reagent. The handling of this new method is simpler than that of the previously used CFA $\mathrm{SO}_{4}{ }^{2-}$ method, especially concerning the reagent preparation. Furthermore, the reagent composition can be adjusted so that a linear calibration curve, also for low concentration levels, is achieved, leading to more accurate and simpler data processing. Compared to the previous method, we found a more stable baseline and a greater suppression of interferences with the volume of the cation exchange column used here. This leads to a more robust application of the method and to more accurate results.

However, the detection limit of the new method is in the same order of magnitude as for the previous method, which is still too high for low background concentration levels. Therefore our method is sufficient and suitable for peak monitoring, but not good enough for accurate background measurements on polar ice samples, especially from interglacial periods.

Despite this drawback, further investigations using the new method will be performed due to the lack of a more sensitive method. To assess the quality of the new method, selected sections of the NGRIP ice core will be re-measured and the new results compared to the values obtained with the previously used $\mathrm{CFA} \mathrm{SO}_{4}{ }^{2-}$ method. We will also try to perform corrections for the asymmetric shape of standard signals and peaks by applying mathematical resolution enhancement techniques such as back-diffusion (Rasmussen and others, 2005) or Monte Carlo approaches.

\section{ACKNOWLEDGEMENTS}

This work is part of the Copenhagen Ice Core Dating Initiative which is supported by a grant from the Carlsberg 
Foundation. We would like to thank K.-H. Schwarz from Sachtleben Chemie $\mathrm{GmbH}$, Germany, for providing a barite test sample.

\section{REFERENCES}

Amirzadeh-Asl, D. and K.-H. Schwarz. 2001. Sachtleben Chemie. DE Pat. 10005685. Germany.

Bigler, M. 2000. Entwicklung und Anwendung einer neuen Methode zur kontinuierlichen, hochaufgelösten Messung der Sulfatkonzentration an alpinen und polaren Eisbohrkernen. (MSc thesis, University of Bern.)

Bigler, M. 2004. Hochauflösende Spurenstoffmessungen an polaren Eisbohrkernen: Glazio-chemische und klimatische Prozessstudien. (PhD thesis, University of Bern.)

Bigler, M. and 6 others. 2002. Sulphate record from a northeast Greenland ice core over the last 1200 years based on continuous flow analysis. Ann. Glaciol., 35, 250-256.

Bigler, M., R. Röthlisberger, F. Lambert, T.F. Stocker and D. Wagenbach. 2006. Aerosol deposited in East Antarctica over the last glacial cycle: detailed apportionment of continental and sea-salt contributions. J. Geophys. Res., 111, D08205. (10.1029/ 2005JD006469.)

Burakham, R., K. Higuchi, M. Oshima, K. Grudpan and S. Motomizu. 2004. Flow injection spectrophotometry coupled with a crushed barium sulfate reactor column for the determination of sulfate ion in water samples. Talanta, 64(5), 1147-1150.

Castellano, E. and 9 others. 2005. Holocene volcanic history as recorded in the sulfate stratigraphy of the European Project for Ice Coring in Antarctica Dome C (EDC96) ice core. J. Geophys. Res., 110, D06114. (10.1029/2004JD005259.)

Clausen, H.B. and 6 others. 1997. A comparison of the volcanic records over the past 4000 years from the Greenland Ice Core Project and Dye 3 Greenland ice cores. J. Geophys. Res., 102(C12), 26,707-26,723

Crowley, T.J. 2000. Causes of climate change over the past 1000 years. Science, 289(5477), 270-277.

Grönvold, K. and 6 others. 1995. Ash layers from Iceland in the Greenland GRIP ice core correlated with oceanic and land sediments. Earth Planet. Sci. Lett., 135(1-4), 149-155.

Hammer, C.U., H.B. Clausen and W. Dansgaard. 1980. Greenland ice sheet evidence of post-glacial volcanism and its climatic impact. Nature, 288(5788), 230-235.

Hegerl, G.C., T.J. Crowley, W.T. Hyde and D.J. Frame. 2006. Climate sensitivity constrained by temperature reconstructions over the past seven centuries. Nature, 440(7087), 1029-1032.

Kondo, O., H. Miyata and K. Tôei. 1982. Determination of sulfate in river water by flow injection analysis. Anal. Chim. Acta, 134, 353-358.

Legrand, M.R. and R.J. Delmas. 1987. Experimental protocol for the chemical analysis of snow, firn and ice cores. In Jones, H.G. and W.J. Orville-Thomas, eds. Seasonal snowcovers: physics, chemistry, hydrology. Dordrecht, etc., D. Reidel Publishing
Co., 225-254. (NATO ASI Series C: Mathematical and Physical Sciences 211.)

Legrand, M. and P. Mayewski. 1997. Glaciochemistry of polar ice cores: a review. Rev. Geophys., 35(3), 219-243.

Littot, G.C. and 9 others. 2002. Comparison of analytical methods used for measuring major ions in the EPICA Dome C (Antarctica) ice core. Ann. Glaciol., 35, 299-305.

Madsen, B.C. and R.C. Murphy. 1981. Flow injection and photometric determination of sulphate in rainwater with methylthymol blue. Anal. Chem., 53(12), 1924-1926.

Mortensen, A.K., M. Bigler, K. Grönvold, J.P. Steffensen and S.J. Johnsen. 2005. Volcanic ash layers from the Last Glacial Termination in the NGRIP ice core. J. Quaternary Sci., 20(3), 209-219.

North Greenland Ice Core Project members. 2004. High-resolution record of Northern Hemisphere climate extending into the last interglacial period. Nature, 431(7005), 147-151.

Osterberg, E.C., M.J. Handley, S.B. Sneed, P.A. Mayewski and K.J. Kreutz. 2006. Continuous ice core melter system with discrete sampling for major ion, trace element, and stable isotope analyses. Environ. Sci. Technol., 40(10), 3355-3361.

Rasmussen, S.O., K.K. Andersen, S.J. Johnsen, M. Bigler and T. McCormack. 2005. Deconvolution-based resolution enhancement of chemical ice core records obtained by continuous flow analysis. J. Geophys. Res., 110, D17304. (10.1029/ 2004JD005717.)

Rasmussen, S.O. and 15 others. 2006. A new Greenland ice core chronology for the last glacial termination. J. Geophys. Res., 111(D06102). (10.1029/2005JD006079.)

Röthlisberger, R. and 6 others. 2000. Technique for continuous high-resolution analysis of trace substances in firn and ice cores. Envir. Sci. Technol., 34(2), 338-342.

Sigg, A., K. Fuhrer, M. Anklin, T. Staffelbach and D. Zurmuehle. 1994. A continuous analysis technique for trace species in ice cores. Environ. Sci. Technol., 28(2), 204-209.

Sommer, S., D. Wagenbach, R. Mulvaney and H. Fischer. 2000. Glacio-chemical study spanning the past $2 \mathrm{kyr}$ on three ice cores from Dronning Maud Land, Antarctica. 2. Seasonally resolved chemical records. J. Geophys. Res., 105(D24), 29,423-29,433.

Udisti, R. and 6 others. 2000. Holocene electrical and chemical measurements from the EPICA-Dome C ice core. Ann. Glaciol. 30, 20-26.

Wolff, E.W. and 27others. 2006. Southern Ocean sea-ice extent, productivity and iron flux over the past eight glacial cycles. Nature, 440(7083), 491-496.

Yang, Y., X.-X. Zhang and T. Korenaga. 1997a. Determination of sulfur dioxide in Southeast Asia by flow injection analysis with on-line reaction column. Anal. Sci., 13 (suppl.), 397-400.

Yang, Y., X.-X. Zhang, T. Korenaga and K. Higuchi. 1997b. Determination of passive-sampled sulphur dioxide in ambient air as sulphate ion by flow injection analysis with an in-line reaction column. Talanta, 45(2), 445-450.

Zielinski, G.A., P.A. Mayewski, L.D. Meeker, S.I. Whitlow and M.S. Twickler. 1996. 110,000-yr record of explosive volcanism from the GISP2 (Greenland) ice core. Quat. Res., 45(2), 109-118. 